ORIGINAL ARTICLE

\title{
Safety culture assessment in community pharmacy: development, face validity, and feasibility of the Manchester Patient Safety Assessment Framework
}

\author{
D M Ashcroft, C Morecroft, D Parker, P R Noyce
}

Qual Saf Health Care 2005;14:417-421. doi: 10.1136/qshc.2005.014332

See end of article for authors' affiliations

....................

Correspondence to: Dr D M Ashcroft, Senior Clinical Lecturer, School of Pharmacy and Pharmaceutical Sciences, University of Manchester, Oxford Road, Manchester M13 9PL, UK; darren. ashcroft@manchester.ac. uk

Accepted for publication 4 September 2005

\begin{abstract}
Objective: To develop a framework that could be used by community pharmacies to self-assess their current level of safety culture maturity, which has high face validity and is both acceptable and feasible for use in this setting.

Design: An iterative review process in which the framework was developed and evaluated through a series of 10 focus groups with a purposive sample of 67 community pharmacists and support staff in the UK. Main outcome measures: Development of the framework and qualitative process feedback on its acceptability, face validity, and feasibility for use in community pharmacies.

Results: Using this process, a version of the Manchester Patient Safety Assessment Framework (MaPSAF) was developed that is suitable for application to community pharmacies. The participants were able to understand the concepts, recognised differences between the five stages of safety culture maturity, and concurred with the descriptions from personal experience. They also indicated that they would be willing to use the framework but recognised that staff would require protected time in order to complete the assessment.

Conclusions: In practice the MaPSAF is likely to have a number of uses including raising awareness about patient safety and illustrating any differences in perception between staff, stimulating discussion about the strengths and weaknesses of patient safety culture within the pharmacy, identifying areas for improvement, and evaluating patient safety interventions and tracking changes over time. This will support the development of a mature safety culture in community pharmacies.
\end{abstract}

Safety culture assessments have been developed in a range of high risk industries. ${ }^{10}$ In health care, assessments of safety culture have predominantly focused on the hospital setting, ${ }^{11-13}$ although recent developments have resulted in tools aimed at assessing the prevailing safety culture in general practice. ${ }^{14}$ The aim of this study was to develop a framework that could be used by community pharmacies to self-assess their current level of safety culture maturity. Specifically, we aimed to develop a self-assessment framework that had high face validity and was both acceptable and feasible for use in community pharmacies.

\section{METHODS}

\section{Theoretical framework}

In 1993 Westrum $^{15}$ developed the original theoretical framework underpinning the Manchester Patient Safety Assessment Framework (MaPSAF). He proposed that one way of distinguishing between organisational cultures is the way in which information is handled by organisations. He identified three levels of organisational culture: pathological, bureaucratic (calculative), and generative. In pathological organisations, failure is often concealed and people refuse to acknowledge that problems exist. In contrast, bureaucratic organisations do not suppress problems but they sometimes make light of them or deal with only the presenting symptoms, while in generative organisations, people have a "licence to think", investigating the root causes of problems, taking responsibility for the findings, and disseminating solutions. ${ }^{1617}$

Reason $^{18}$ and, more recently, Parker and Hudson ${ }^{19}$ extended this framework and applied it to safety culture, incorporating a range of safety behaviours at five levels of culture assessment tools provide an avenue towards such understanding. ${ }^{3}$ 


\begin{tabular}{|ll|}
\hline Table 1 & Levels of organisational safety culture \\
\hline $\begin{array}{l}\text { Level of } \\
\text { organisational } \\
\text { safety culture }\end{array}$ & Characterisation \\
\hline Level 1: & Why do we need to waste our time on \\
Pathological & risk management and safety issues? \\
Level 2: & We take risk seriously and do something \\
Reactive & every time we have an incident. \\
Level 3: & We have systems in place to manage all \\
Calculative & likely risks. \\
Level $4:$ & We are always on the alert, thinking \\
Proactive & about risks that might emerge. \\
Level 5: & Risk management is an integral part of \\
Generative & everything we do. \\
\hline & \\
\hline
\end{tabular}

organisational safety culture (table 1). The additional levels added more depth to the original framework, allowing for more subtle classification and clarifying the idea that organisations would be expected to progress with increasing maturity through the different levels of safety culture.

\section{Applying the framework to community pharmacy Orientation with the framework}

The MaPSAF has previously been developed in health care for use in primary care trusts (PCTs) and their constituent general practices in the UK. ${ }^{14}$ The process used to apply the framework to safety culture in community pharmacy was iterative. Firstly, we held a focus group with four practising community pharmacists who reviewed the framework that had been developed for PCTs and general practices with a view to developing a version suitable for use in community pharmacies. Written comments were also received from two further community pharmacists who were unable to attend the meeting. All of the pharmacists felt that the framework could be adapted for use in community pharmacy and subsequently identified the following eight dimensions of patient safety that were considered to be applicable to community pharmacy:

- Commitment to patient safety

- Perceptions of the causes of incidents and their reporting

- Investigating incidents

- Learning following an incident

- Communication within the pharmacy

- Staff management

- Staff education and training about risk management

- Team working

\section{Focus group discussions}

Ten focus group discussions with community pharmacists and support staff were then used to further develop and evaluate the framework. The focus groups sought to reflect the diversity of staff working in community pharmacies, and this was achieved by purposively selecting participants to ensure broad coverage of the different staff groups (pharmacy owners, employed pharmacists, locum pharmacists, preregistration pharmacists, pharmacy technicians, and pharmacy assistants). Participants were drawn from seven health localities (PCTs) in England. In all, 67 pharmacists and support staff participated in the study, with each focus group containing 4-10 participants. All the focus groups were undertaken between December 2003 and April 2004 at venues local to the participants.

\section{Development of the framework}

In the first six focus groups the content of the framework was refined. In essence, the framework was split into four sections, each covering two of the eight safety dimensions. Participants were asked to review in detail the descriptions contained within one of the sections of the framework to decide if they agreed with the content and to provide any suggestions on how the framework could be improved for use in community pharmacies. All of the four sections of the framework were reviewed in detail over the course of the six focus group meetings. Following each focus group, two members of the research team (DMA, CM) considered all of the issues raised by the participants and made any necessary revisions to the framework. The revised version was circulated at the next focus group meeting.

\section{Evaluation of the framework}

As part of the last four focus groups we presented the framework in its entirety to different participants and asked them to comment on its acceptability, face validity, and feasibility for use in community pharmacies. Each focus group was tape recorded and fully transcribed. All transcripts were read by two members of the research team (DMA, CM) and key themes and areas of interest were identified using content analysis techniques and constant comparative methods. ${ }^{20}$

NVivo software (Version 2.0) was used to apply codes to the transcripts, which allowed subsequent examination of the data for particular themes. The University of Manchester Senate Committee on the Ethics of Research on Human Beings granted ethical approval for the study.

\section{RESULTS}

Using this process, a version of the MaPSAF was developed which was suitable for use in community pharmacies. The framework consists of a matrix in which the five levels of organisational safety culture have been mapped against qualitative statements characterising the eight dimensions of patient safety. For illustrative purposes, the descriptions characterising one of the dimensions (Learning following an incident) are shown in table 2.

\section{Acceptability}

Feedback from the focus group discussions indicated that the MaPSAF was acceptable to the participants who also suggested that the framework would serve to raise awareness about risk management within their workplace.

"I think it makes you think about the whole risk management."

"It's a breakdown of our different reactions and it makes you reflect on your work and your practice."

\section{Face validity}

The participants were able to understand the concepts, recognised differences between the five stages of safety culture maturity, and concurred with the descriptions from personal experience. Furthermore, they felt that the prevailing risk management culture in the majority of community pharmacies could be characterised as pathological.

"I couldn't think of a single pharmacy where they got any further than pathological."

"Most places are still on this pathological stage and they're stuck there, and all they want to do is sort the error out and forget about it. If they can, they sort out an error and if nobody complains about it, then forget it."

"I think from my experience I've probably fitted into all five categories somewhere along the line. You know, we've all been pathological in our time, I'm sure, and then we've all sort of changed the way we put stock on the shelf. We've separated two strengths by another drug, for example." 
Table 2 Descriptions of the levels of safety culture for one of the dimensions

\begin{tabular}{|c|c|}
\hline $\begin{array}{l}\text { Learning following } \\
\text { an incident }\end{array}$ & Description \\
\hline Pathological & $\begin{array}{l}\text { This is not a learning organisation as no attempts } \\
\text { are made to learn from incidents unless imposed by } \\
\text { the pharmacy inspectors. The aim of the pharmacy } \\
\text { after an incident is to "paper over the cracks" and } \\
\text { protect itself. The pharmacy considers that it has } \\
\text { been successful when the inspectors do not become } \\
\text { aware of an incident. No changes are made after } \\
\text { an incident apart from those directed at the } \\
\text { individuals concerned. }\end{array}$ \\
\hline Reactive & $\begin{array}{l}\text { Little if any learning occurs, and what does take } \\
\text { place only relates to the amount of irritation that the } \\
\text { manager/owner has experienced. All learning is } \\
\text { specific to the particular incident. Any changes } \\
\text { made after an incident are not maintained as they } \\
\text { are knee jerk reactions to individual errors and are } \\
\text { devised and imposed by the manager/owner. } \\
\text { Consequently, similar incidents tend to recur. }\end{array}$ \\
\hline Calculative & $\begin{array}{l}\text { Some systems are in place to enable learning to } \\
\text { take place but the lessons learnt are not } \\
\text { communicated throughout the pharmacy. This } \\
\text { learning results in some enforced local changes } \\
\text { that relate directly to the specific incident. The } \\
\text { manger/owner decides on the changes that need } \\
\text { to be introduced and this lack of staff involvement } \\
\text { leads to changes not being integrated into working } \\
\text { patterns. }\end{array}$ \\
\hline Proactive & $\begin{array}{l}\text { The pharmacy has a learning tradition and systems } \\
\text { exist to share learning, such as reflection and audit. } \\
\text { Members of staff are actively involved in deciding } \\
\text { what changes are needed and there is a real } \\
\text { commitment to change throughout the pharmacy. } \\
\text { Hence, changes are maintained. The pharmacy } \\
\text { looks for learning opportunities and is keen to learn } \\
\text { from others' experiences. The learning that follows } \\
\text { incidents is used in forward planning. It is an open } \\
\text { self-confident pharmacy. }\end{array}$ \\
\hline Generative & $\begin{array}{l}\text { The pharmacy learns and shares information about } \\
\text { incidents with staff and other pharmacies. It is } \\
\text { committed to sharing this learning both within the } \\
\text { pharmacy and with other community pharmacies. } \\
\text { Incidents are openly discussed where all staff feel } \\
\text { able to contribute. Incidents are seen as a learning } \\
\text { opportunity; they are inevitable but learning can } \\
\text { occur to reduce their likelihood of occurrence. } \\
\text { Learning within the pharmacy is evaluated. } \\
\text { Improvements in practice occur without a trigger of } \\
\text { an incident as the culture is one of constant } \\
\text { improvement. }\end{array}$ \\
\hline
\end{tabular}

Nonetheless, they recognised that there was a need for an improvement in safety culture within community pharmacy, and the descriptions of more mature cultures presented within the framework provided an indication of where these improvements were required.

"I think I've actually got up to calculative in some areas, but I don't think anybody has got up to the top bit yet at all anywhere."

"I kind of fitted my experience as a locum pharmacist in the community to where I find myself, and it's quite shocking to think that you never ever reach the idea which is generative. And whilst often in pathological, not pathological in terms of myself, but in terms of the support you would get from the organisation, especially if you're a locum pharmacist."

"It tells you where you should be, and I think we then have to think for ourselves how we're going to get into that square."

It appeared that the pharmacy manager or owner had a prime influence on the prevailing safety culture within their organisations.
"He's one step down from God isn't he?"

"In a pharmacy, the staff look up to the pharmacist to do anything."

In some cases, staff reported that they had to comply with the wishes of the pharmacy manager or owner in relation to the reporting of safety incidents.

"Some managers don't like errors being reported and sort of push them under the carpet and you tend to just think, 'Well I can't cause trouble, I can't make trouble', and you tend to keep it to yourself, even when you see something that is wholly unacceptable."

Participants also often referred to the impact that reporting would have on working relationships between colleagues.

"If you were working at a branch five days a week and you want to get along well with the rest of the staff, then it's that element of, you know, if I start reporting them, they're going to start, you know, causing an atmosphere."

The participants repeatedly identified team working in relation to safety issues as an important area for future development, and emphasised the importance of staff training and its impact on patient safety.

"I've got some really good technicians, but in the past they have said 'You made an error, you gave the wrong strength' and it's as if it's the pharmacist's fault. I know we do the end check [on the prescription] and it's our responsibility, but the technician did [assemble] the wrong strength first, so they need to change their practice as well, not just the pharmacist."

"Having staff doing the investigation I think is good, because it empowers them, so they get involved instead of just the pharmacist saying 'Well, this is what we need to do, we need to change things' and then two weeks down the line they've forgotten about it. I think in that respect it's very good, because it's not just one person, not just the pharmacist."

"It's good for team building as well. Everyone's going to aspire to be at the top end ... they are all going to work towards it."

\section{Feasibility}

Most of the participants indicated that they would be willing to use the framework but recognised that staff would require protected time in order to complete the assessment.

"I think if you did give them the time to do it, because that's what you always find when you walk into a community pharmacy and you say, 'Right, I want you to do this'. They'll look at it and go 'And when?' and they will always say that to you. But if you said, 'Sit down and read it', I think a lot of the dispensers could actually do that and do it well."

However, some of the participants did not embrace the concept wholeheartedly, suggesting that other factors were of a higher priority than risk management in the pharmacy.

"Clinical governance, we're doing just this at the moment and it seems very laborious to me."

"Even though I like the idea, even though I think it's a good idea, and if at the end of the day it stops mistakes happening, great, I'm all for it, that's the last thing you want. But there has to be a balance somewhere along the line, and it's getting the balance right, isn't it?"

The participants also recognised that all relevant members of staff needed to complete the framework. Not surprisingly, some of the locum pharmacists explained that, as they were not regularly based in the same community pharmacy, they were not well placed to use the framework as part of a team exercise to evaluate the prevailing safety culture in specific pharmacies.

"I do find that this is great if you are in one place all the time. I work in some stores regularly and others I just wander around, but when you wander around you walk into whatever you see and that's what you get, and they [the staff] will not necessarily change the way they dispense to fit you, you've got to change your way within reason to fit them."

However, in general the participants recognised that there was a need for a cultural shift within the community 
pharmacy with regard to patient safety, and felt that the framework could be used to facilitate this process, particularly if it was used in a focus group setting. It was acknowledged, however, that one of the key challenges would be to overcome the sensitivities around sharing information between different pharmacies.

"I think it's a culture change. It's moving towards the right on your tool really. It's fostering an attitude towards clinical governance, so that you're continually reflecting on your practice, whether that is in a dispensary setting or an OTC (over the counter) setting. Looking at the standards, looking at the patient outcomes, and looking at how those can be improved. Not getting hung up on the nature of your protocol, but getting hung up on the fact that you have to go through those thought patterns and not just you but all your employees, your staff, your technicians. Everybody should be thinking about it in a clinical governance way or is what we're doing the best way of doing it. So it's how you get that philosophy from top right down to the bottom, without getting too hung up on the processes in between. You know, have we got this written down, let's write all that, but making that culture change in your mind and in your staffs' minds. Then also, the next bit, the exciting bit after that is then having some kind of group, like this one, where you then share those experiences and you start to benchmark, you start to say, 'Well, these are our experiences, is that good or bad?' And then you try and work it out. Now, whether that would happen, because we're all in competition with each other, I'm not so sure. But it's a way of trying to work that out so it can be done in a way to drive quality."

\section{DISCUSSION}

The safety culture approach to risk management emphasises the role played by social forces within an organisation and their impact on the individual operator's cognitions, perceptions, and behaviour with respect to safety at work. ${ }^{4}$ Schein ${ }^{21}$ suggests that the way in which managers instruct, reward, allocate their attention, and behave under pressure are particularly important in shaping organisational culture. The perceptions of managers' attitudes and behaviours in relation to safety and well being of the workforce will therefore form the basis for the safety behaviour of workers and the safety performance of the company. ${ }^{4}$ Reason $^{5}$ proposed that an organisation's safety culture takes on a profound significance at the point where accident rates reach a "plateau". In order to go beyond this "low but [seemingly] unassailable" plateau and to continue improvement in safety performance, it is necessary to address the hearts and minds of the management and workers. ${ }^{22}$ In high hazard and complex working environments, effective leadership has been shown to improve safety performance. ${ }^{17}{ }^{23}$

This study is concerned with the safety culture in community pharmacies. In a typical pharmacy $1-3$ staff members are involved in dispensing 20-60 prescription items per hour. The process is demand driven with patients randomly presenting prescriptions and waiting in the pharmacy for their dispensed medicines. For most pharmacies, maintaining an adequate volume of dispensing determines their viability. Speed of dispensing is therefore a priority, resulting in bursts of intense dispensing activity. Organisation and participation of different players in the dispensing process significantly depends on the level of activity.

Two key influences on the safety culture of a particular pharmacy are its ownership and staffing. Community pharmacies may be owned and managed by an individual pharmacist or be in corporate ownership. Some pharmacy companies sustain strong company cultures and reporting systems, and others much less so. Every pharmacy has to have a pharmacist directly supervising the dispensing operation who, if he or she is the permanent manager, may be the primary influence in determining the safety culture or, if simply providing cover for the day as a locum, may have little influence. Earlier work has shown the difference in professional autonomy exercised by community pharmacists of different occupational status, with locums being significantly less assertive than owners. ${ }^{24}$

By involving pharmacy staff, we have developed a version of the MaPSAF that will enable community pharmacies to evaluate their patient safety culture. In practice, we anticipate that the MaPSAF will have a range of uses which include: (1) raising awareness about patient safety and illustrating any differences in perception between staff; (2) stimulating discussion about the strengths and weaknesses of patient safety culture within the pharmacy; (3) identifying areas for improvement; (4) evaluating patient safety interventions and tracking changes over time; and (5) conducting internal and external benchmarking exercises. ${ }^{3}$ However, the assessment process will require the commitment of staff and time. It will be important to ensure that all regular members of staff are involved in the assessment process as the findings are likely to point to many different areas in which the prevailing safety culture could be improved.

The effectiveness of the MaPSAF will also depend on the development of a shared understanding among staff of the underlying meanings of the results of the assessment, and subsequently identifying the means by which improvements in patient safety culture can be achieved. Rather than viewing the assessment results as the end point, the information should be considered the starting point from which action and patient safety changes emerge. ${ }^{3}$ In other high risk industries, improvements in safety have largely been achieved by the stepwise implementation of hundreds of small changes in procedures, equipment, training, and organisation that have culminated in establishing effective working practices and a strong safety culture. ${ }^{25}$ Likewise, in order to improve the prevailing safety culture in community pharmacy, it is expected that incremental changes will need to be implemented and tested on a small scale, changing and evaluating the impact of one process or practice at a time.

Community pharmacists and support staff helped to develop this framework for use in their own workplace by modifying an existing instrument developed in ambulatory care using an iterative review process. Face validity is therefore high, and comments from the focus group participants also indicate that the framework is both acceptable and feasible for use in this setting. Furthermore, the qualitative findings suggest that there is room for improvement in the prevailing safety culture within a community pharmacy. Other empirical evidence also suggests that under-reporting of patient safety incidents is likely to be a significant problem in this setting. ${ }^{26}$

Safety improvement strategies require that organisations have ready access to information that supports learning from experience in order to promote systems that both prevent and mitigate the impact of errors. ${ }^{27}$ In contrast to a pathological culture where failure is concealed and people refuse to acknowledge that problems exist, a generative safety culture recognises the inevitability of error and proactively seeks to identify latent threats. ${ }^{35}$ It is encouraging that the participants felt that the descriptions of more mature safety cultures pointed to areas for further improvement, suggesting that the framework might encourage users to engage in "double loop" organisational learning at the higher levels of safety maturity whereby learning from experience becomes second nature and part of routine practice. ${ }^{28}$ However, further work will be needed to address these issues fully, in particular to examine in greater depth the instrument's other psychometric properties including measures of internal consistency, reliability and construct validity. In the meantime, it is hoped that the framework will assist community pharmacists and their 
support staff in their efforts to improve the safety culture within community pharmacies.

\section{ACKNOWLEDGEMENTS}

The authors thank all the pharmacists and support staff who helped to develop and evaluate the MaPSAF.

\section{Authors' affiliations}

D M Ashcroft, C Morecroft, P R Noyce, School of Pharmacy and Pharmaceutical Sciences, University of Manchester, UK D Parker, School of Psychological Sciences, University of Manchester, UK

This study was funded by the Community Pharmacy Research Consortium

\section{Conflicts of interest: none}

The community pharmacy version of the MaPSAF can be obtained from the Centre for Innovation in Practice, School of Pharmacy and Pharmaceutical Sciences, University of Manchester at www.manchester. ac.uk/CIP.

\section{REFERENCES}

1 Helmreich RL, Merritt AC. Culture at work in aviation and medicine: national, organizational, and professional influences. Aldershot: Ashgate Publishing, 1998.

2 Scott T, Mannion R, Davies $\mathrm{H}$, et al. The quantitative measurement of organisational culture in health care: a review of the available instruments. Health Serv Res 2003;38:923-45.

3 Nieva VF, Sorra J. Safety culture assessment: a tool for improving patient safety in healthcare organizations. Qual Saf Health Care 2003;12(Suppl II):ii17-23.

4 Clarke S. Perceptions of organisational safety: implications for the development of safety culture. J Organ Behav 1999;20:185-98.

5 Reason J. Safety paradoxes and safety culture. Injury Control Saf Prevent 2000;7:3-14

6 Department of Health. An organisation with a memory. Report from an expert working group on learning from adverse events in the NHS. London: Department of Health, 2000.

7 Institute of Medicine. Crossing the quality chasm: a new health system for the 21 st century. Washington, DC: National Academy Press, 2001.

8 National Patient Safety Agency. Seven steps to patient safety: a guide for NHS staff. London: National Patient Safety Agency, 2004.

9 Institute of Medicine. To err is human: building a safer health system. Report of the Committee on Quality of Health Care in America. Washington, DC: National Academy Press, 2000
10 Guldenmund FW. The nature of safety culture: a review of theory and research. Saf Sci 2000;34:215-57.

11 Pronovost PJ, Weast B, Holzmueller CG, et al. Evaluation of the culture of safety: survey of clinicians and managers in an academic medical center. Qual Saf Health Care 2003;12:405-10.

12 Weingart SN, Farbstein K, Davis RB, et al. Using a multihospital survey to examine the safety culture. It Comm J Qual Saf 2004;30:125-32.

13 Singer SJ, Gaba DM, Geppert JJ, et al. The culture of safety: results of an organization-wide survey in 15 California hospitals. Qual Saf Health Care 2003; 12:112-8.

14 Parker D, Kirk S, Claridge T, et al. The Manchester Patient Safety Assessment Tool, National Primary Care Research and Development Centre, University of Manchester, 2002.

15 Westrum R. Cultures with requisite imagination. In: Wise JA, Hopkin VD, Stager $\mathrm{P}$, eds. Verification and validation of complex systems: human factor issues. New York: Springer-Verlag, 1993:401-16.

16 Westrum R. Organisational dynamics and safety. In: McDonald N, Johnston N, Fuller R, eds. Applications of psychology to the aviation system. Proceedings of the 21 st Conference of the European Association for Aviation Psychology (EAAP). Aldershot: Ashgate Publishing, 1995:75-80.

17 Westrum R. A typology of organisational cultures. Qual Saf Health Care 2004; 13(Suppl II):ii22-7.

18 Reason J. The identification of latent organizational failures in complex systems. In: Wise JA, Hopkin VD, Stager P, eds. Verification and identification of complex systems: human factor issues. New York: Springer-Verlag, 1993:223-37.

19 Parker D, Hudson PT. Understanding your culture. EP 2001-5124. Shell International Exploration and Production, 2001.

20 Strauss A, Corbin J. Basics of qualitative research: grounded theory procedures and techniques. Newbury Park, CA: Sage, 1990.

21 Schein EH. Organisational culture and leadership. San Francisco: JosseyBass, 1992.

22 Lee T. Assessment of safety culture at a nuclear reprocessing plant. Work and Stress 1998; 12:217-37.

23 Flin R, Yule S. Leadership for safety: industrial experience. Qual Saf Health Care 2004; 13(Suppl II):ii45-51.

24 Magirr P, Grimsley M, Ottewill R, et al. Clinical autonomy of community pharmacists in England: (2) Key findings. Int J Pharm Prac 2004; 12:231-8.

25 Leape LL, Berwick DM, Bates DW. What practices will most improve safety? Evidence-based medicine meets patient safety. JAMA 2002;288:501-7.

26 Ashcroft D, Morecroft C, Parker D, et al. Patient safety in community pharmacy: understanding errors and managing risk. London: Royal Pharmaceutical Society of Great Britain, 2005.

27 Reason J. Organisational accidents: the management of human and organisational factors in hazardous technologies. Cambridge: Cambridge University Press, 1997

28 Reason JT, Carthey J, de Leval MR. Diagnosing "vulnerable system syndrome": an essential prerequisite to effective risk management. Qual Health Care 2001; 10(Suppl II):ii21-5.

\section{1 th European Forum on Quality Improvement in Health Care}

26-28 April 2006, Prague, Czech Republic

For further information please go to: www.quality.bmipg.com

Book early to benefit from a discounted delegate rate 